\title{
Anarquismo(s) y feminismo(s). Reflexiones a partir de las intervenciones de las mujeres anarquistas, Buenos Aires (1896-1947)
}

\author{
Anarchism(s) and feminism(s). Considerations on the interventions of \\ anarchist women, Buenos Aires (1896-1947)
}

\author{
Nadia Ledesma Prietto*
}

Resumen: En este trabajo nos interesa problematizar la relación entre anarquismo y feminismo en perspectiva histórica a través del análisis de las intervenciones de las mujeres anarquistas en el ámbito local desde fines de siglo XIX hasta la primera mitad del siglo XX. Visibilizaremos las continuidades e inflexiones discursivas y reflexionaremos sobre su identificación con el feminismo, teniendo en cuenta las conceptualizaciones de las propias mujeres en relación con el contexto de locución.

Palabras Clave: Mujeres, anarquismo, feminismo, prensa escrita, interseccionalidad

\begin{abstract}
In this paper we attempt a problematization of the relationship between anarchism and feminism in a historical perspective, through the analysis of the interventions of anarchist women in a local scale since the late $19^{\text {th }}$ century until mid $20^{\text {th }}$ century. We will make visible the continuities and breaking points in the discourse, and ponder about their identification with feminism, considering the conceptualization of the very women in relation with the context of their speech.
\end{abstract}

Keywords: Women, anarchism, feminism, written press, intersectionality

Recibido: 10 enero 2017

Aceptado: 7 marzo 2017

\footnotetext{
* Argentina, Doctora en Historia (UNLP), Becaria Posdoctoral CONICET. Pertenencia institucional: CInIGIdIHCS/CONICET-FaHCE-UNLP-CONICET.Correo electrónico: nadialedesmaprietto@yahoo.com.ar. Este estudio es una versión revisada y ampliada de un trabajo final presentado para el Seminario de posgrado "Filosofía política feminista y Teoría de Género" dictado por la Dra. María Luisa Femenías en la Facultad de Humanidades y Ciencias de la Educación de la Universidad Nacional de La Plata. Agradezco la lectura atenta de Gisela Manzoni y los comentarios y sugerencias de lxs evaluadorxs.
} 
A palavra 'feminismo', de significação elástica, deturpada, corrompida, mal interpretada, já não diz nada das reivindicações

feministas. Resvalou para o ridículo, numa concepção vaga, adaptada incondicionalmente a tudo quanto se refere à mulher. María Lacerda de Moura, 1919

\section{Introducción}

Los vínculos entre los feminismos y los partidos y expresiones políticas, desde la derecha hasta la izquierda, siguen siendo problemáticos, más aún, cuando en situaciones coyunturales se pone en evidencia los límites del compromiso con la consecución de derechos al replantearse sí la búsqueda de igualdad en términos de género forma parte de las plataformas e idearios de los partidos y movimientos. ${ }^{1}$ Esta cuestión no es nueva, podríamos remontarnos, siguiendo a Joan Scott, a la emergencia del individualismo liberal, siendo el feminismo occidental un "producto" de este y en particular "un síntoma de sus contradicciones constitutivas". 2

En este trabajo, no pretendemos dilucidar esta controversia, pero sí nos interesa reflexionar sobre ella, a través del análisis histórico de la definición de feminismo en relación con las manifestaciones de las mujeres anarquistas en Argentina desde fines de siglo XIX hasta la primera mitad del siglo XX. El movimiento anarquista, dentro de las izquierdas, adquiere un carácter particular dado que, a partir de la perspectiva de Mikhail Bakunin, el anarquismo conllevó per se en su pensamiento la igualdad entre varones y mujeres como así también la emancipación social e individual. ${ }^{3}$ Sin embargo, como veremos a continuación, las mujeres anarquistas denunciaban que resultaba difícil implementar estas premisas.

La Voz de la Mujer ${ }^{4}$ (1896-1897) y Nuestra Tribuna ${ }^{5}$ (1922-1925) son los dos periódicos anarquistas conocidos hasta el momento escritos exclusivamente por mujeres en

\footnotetext{
${ }^{1}$ En nuestro país los debates afloran durante los Encuentros Nacionales de Mujeres que se realizan una vez al año y, desde el año 2015, en movilizaciones claves contra la violencia machista como "Ni una Menos" y la convocatoria al "paro de mujeres" el 19 de octubre de 2016. Sobre debates contemporáneos entre las izquierdas y los feminismos consultar Laura Fernández Cordero, "Izquierdas y feminismos, hitos contemporáneos", Nueva Sociedad, 261, Enero - Febrero, 2016, 116-127. Disponible en http://nuso.org/media/articles/downloads/7.TC_Fernandez_261.pdf.

${ }^{2}$ Joan Scott, Las mujeres y los derechos del hombre. Feminismo y sufragio en Francia, 1789-1944, Buenos Aires, Siglo XXI, 2012, 37.

${ }^{3}$ Laura Vicente, "El feminismo anarquista desde sus orígenes internacionalistas a Mujeres Libres", Viento Sur, $\quad N^{\circ} \quad 136, \quad$ octubre, 2014, $\quad 90-98 . \quad$ Disponible en, https://vientosur.info/IMG/pdf/VS136_L_Vicente_El_feminismo_anarquista_desde_sus_origenes internacion alistas_a_Mujeres_Libres.pdf; Adriana Palomera Valenzuela, "La mujer anarquista: Discursos en torno a la construcción de sujeto femenino revolucionario en los albores de la "idea"', Izquierdas, N 24, Julio, 2015. Disponible en: https://dx.doi.org/10.4067/S0718-50492015000300008

${ }^{4}$ Se publicaron 9 números del periódico entre el 8 de enero de 1896 y el $1^{\circ}$ de enero de 1897 , de aparición irregular, se sostenía a partir de suscripciones voluntarias. La impresión del periódico oscilaba entre mil y dos
} 
el ámbito local, estas substanciales fuentes históricas han sido examinadas de manera particular atendiendo a su relación con el feminismo. Las ideas y las prácticas de las mujeres que participaron en esta prensa son identificadas en diversos estudios como feministas y se las considera como precursoras del feminismo en el ámbito local. Algunos de estos abordajes producen cierta homogenización, anacronismo e imposiciones de identidad -más aún cuando son citados por otros estudios que no se especializan en el tema-, al no esclarecer desde qué definición de feminismo parten y también al situar en segundo plano qué pensaban sobre él las protagonistas de los emprendimientos periodísticos. Asimismo, entendemos que la preocupación por establecer conexiones feministas ha producido la obliteración de la identidad política anarquista de estas mujeres.

Por ello, en este trabajo, por un lado, siguiendo la propuesta de Karen Offen ${ }^{6}$ para identificar ideas y prácticas feministas, examinaremos a través de un estudio comparativo las dos publicaciones mencionadas y traeremos a escena "La página de la mujer", sección del periódico libertario Reconstruir (1946-1959) escrita por mujeres. Por otro lado, en este ejercicio, tendremos en cuenta las conceptualizaciones de las ácratas sobre el feminismo de su época teniendo en cuenta las continuidades y discontinuidades producidas desde fines del siglo XIX hasta la primera mitad del siglo XX. Igualmente, tendremos en cuenta la interseccionalidad con la cuestión de clase y las ideas políticas que defendían las mujeres anarquistas en los diferentes períodos. Sostenemos que las inflexiones y cambios en sus narrativas desde fines del siglo XIX hasta la mitad del siglo XX con respecto al lugar de las mujeres en la sociedad, está influenciada por su origen social y por lo que para ellas encarnaba el anarquismo, dos cuestiones que no deben desestimarse.

En este recorrido, brevemente presentaremos una revisión bibliográfica sobre el tema, en particular, destacaremos las definiciones de feminismo que se utilizan para identificar a las mujeres ácratas. Luego, examinaremos cada uno de los momentos discursivos a partir de las conceptualizaciones de Offen, atendiendo a las permanencias y los cambios en la enunciación focalizaremos en las consideraciones de las propias anarquistas sobre el feminismo según los diversos contextos. Así, a través de este estudio, no sólo visibilizaremos las intervenciones de las mujeres en la prensa, sino que nos interesa particularmente, problematizar y reflexionar sobre los usos del feminismo como conceptualización no situada para identificar ideas y prácticas y, de manera más general, contribuir a la discusión sobre los enrevesados vínculos entre los feminismos y los partidos y expresiones políticas.

mil ejemplares de cuatro páginas. En la re- edición del periódico en 1997, de los ejemplares encontrados en el Instituto de Historia Social de Ámsterdam, no se encontró el n ${ }^{\circ} 6$ del cual hasta el momento no hay datos. Las referencias sobre La Voz de la Mujer provienen de la edición del año 2002.

${ }^{5}$ El periódico contó con 39 números, publicados entre 1922 y 1925 , que alcanzaron un tiraje de cuatro mil ejemplares a través de suscripciones. De alcance internacional, el periódico fue re- editado en 2005 en la versión de facsímil encontrada en el Instituto de Historia Social de Ámsterdam por Elsa Calzetta. Las referencias a Nuestra Tribuna provienen de esta re-edición. Nuestra Tribuna, hojita del sentir anárquico femenino (1922-1925), Bahía Blanca, Universidad Nacional del Sur, 2005.

${ }^{6}$ Karen Offen, "Definir el feminismo: un análisis histórico comparativo", Historia Social, N9, invierno, 1991, 103-135, 131. El artículo se publicó originalmente en la revista Signs. Journal of Women in Culture and Society, vol.14, $\mathrm{N}^{\circ} 1,1988$ 


\section{La historiografía local y el feminismo de las mujeres anarquistas}

Los primeros estudios realizados por destacadas historiadoras y feministas locales sobre el periódico La Voz de la Mujer, establecieron un horizonte de sentido para posteriores abordajes que de manera tangencial abordaron el "feminismo anarquista" ${ }^{7}$ De igual modo, entendemos que aquellas iniciales pesquisas sobre el fenómeno retomaron algunas de las interpretaciones trazadas en 1986 por Maxine Molyneux en su trabajo publicado en la revista Latin American Perspectives, bajo el título "Ni dios, ni patrón, ni marido. Feminismo anarquista en la Argentina del siglo XIX". ${ }^{8}$ Este estudio preliminar sobre la $\mathrm{La}$ Voz de la Mujer catalogó las ideas de las anarquistas como "una fusión de ideas feministas con orientación revolucionaria y trabajadora", intersectando la cuestión de género con la cuestión de clase. ${ }^{9}$

En las diversos análisis se reprodujo una imagen de las mujeres ácratas que las definía como vanguardia del feminismo en Argentina centrada en la defensa del placer y en subvertir cuestiones del ámbito privado, cuestiones que las distinguían del feminismo burgués ocupado en reivindicaciones sufragistas. ${ }^{10}$ Definiciones como "feminismo obrero" y "anarco-feminismo latino"12 -por la importancia otorgada a la maternidad- se esgrimieron para caracterizar a las mujeres del periódico. Además, en algunos casos, la identidad anarquista de las mujeres ha sido evidenciada en segundo plano y su feminismo fue señalado como lo que las había conducido a participar del movimiento ácrata. ${ }^{13}$

Con relación al tratamiento historiográfico del periódico Nuestra Tribuna, sus redactoras y su práctica también ha sido considerada feminista. Según Marcela Nari, más allá de su propia autodefinición, se las identifica así, pues reconocen la subordinación de las mujeres en relación a los varones e intentan cambiarla. ${ }^{14}$ En este mismo sentido, se las examina como las antecesoras de las propuestas del feminismo de los años sesenta en relación con la discriminación femenina y la sexualidad. ${ }^{15}$

\footnotetext{
${ }^{7}$ Mabel Bellucci, "De la pluma a la imprenta”, Lea Fletcher (comp.), Mujer y cultura en la argentina del siglo XIX, Buenos Aires, Feminaria editora, 252-262, 1994; Marcela Nari y María del Carmen Feijoó, "Imaginando al lector/ la lectora de la Voz de la Mujer", Lea Fletcher, (comp.) Mujer y cultura en la argentina del siglo XIX, Buenos Aires, Feminaria editora, 276-284, 1994. Una aproximación al problema de definir el feminismo anarquista en Laura Fernández Cordero, "Introducción al Dossier: una cuestión palpitante. Versiones del

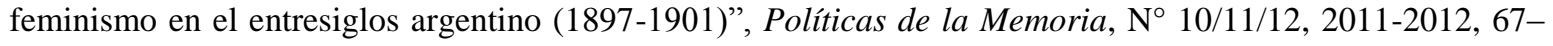
95.

${ }^{8}$ Título original: "No God, No boss, No Husband: Anarchist Feminism in Nineteenth- Century Argentina"

${ }^{9}$ Molineaux, Maxine, "Ni dios, ni patrón, ni marido. Feminismo anarquista en la argentina del siglo XIX", La Voz de la Mujer. Periódico comunista -anárquico. 2da. ed. Buenos Aires, Universidad Nacional de Quilmes, 2002,11-40,11-12.

${ }^{10}$ Bellucci, op. cit.

${ }^{11}$ Dora Barrancos, Anarquismo, educación y costumbres en la argentina de principios de siglo, Buenos Aires, Contrapunto, 1990, 282.

${ }^{12}$ Cristina Guzzo, Las anarquistas rioplatenses (1890-1990), EEUU, Orbis Press, 2003, 32.

${ }^{13}$ Molineaux, op. cit.

${ }^{14}$ Marcela Nari, "el feminismo frente a la cuestión de la mujer en las primeras décadas del siglo xx", Juan Suriano (comp.), La cuestión social en argentina, 1870-1943, Buenos Aires, La colmena, 2004.

${ }^{15}$ Mabel Bellucci, “Anarquismo y feminismo”, El libertario, año 21, n 67, 2006.
} 
En otros estudios se ha complejizado su caracterización. Dora Barrancos, definió como "contrafeminismo" la posición del anarquismo, para dar cuenta de "la resistencia del feminismo anarquista al feminismo burgués y reformista en la búsqueda de obtención de las prerrogativas civiles y cívicas". ${ }^{16}$ La autora señala que esta postura debe interpretarse como constitutiva de la doctrina del movimiento, para evitar consideraciones erróneas. Más tarde, en su análisis del periódico Nuestra Tribuna, para caracterizar y contextualizar con más precisión las intervenciones de las mujeres anarquistas en la década de 1920, Barrancos utiliza el concepto, precisado por Karen Offen, de "feminismo relacional". Este define a "...las fuerzas sociales que de diferentes maneras se oponen al capitalismo y pretenden horadar -y hasta suprimir- el orden burgués", que reúne identidades diversas pero que están ligadas alrededor del cuestionamiento del funcionamiento de la sociedad con la que interactúan y enfatizan en la 'complementariedad' "estampada, no sobre la igualdad, sino en la diferencia con el otro género". ${ }^{17}$ Este posicionamiento se contrapone a los argumentos de la tradición feminista individualista, que, según Offen, "hacían hincapié en los conceptos más abstractos de los derechos humanos individuales y exaltaban la búsqueda de la independencia personal (o autonomía) en todos los aspectos de la vida". ${ }^{18}$ Se oponían a la complementariedad y a los roles definidos por la sociedad a partir de las "diferencias de sexo", las cuales minimizaban. ${ }^{19}$

La participación de las mujeres libertarias en la sección "La página de la mujer" del periódico Reconstruir, ha sido exiguamente estudiada. Desde una mirada preliminar, se hace hincapié en la particularidad de un discurso más afable con el feminismo de la época de las décadas de 1940 y 1950, el cual diferenciaban del sufragismo. María Eugenia Bordagaray señala que en ese contexto histórico la movilización política de las mujeres realizada desde el gobierno peronista por la primera dama Eva Duarte resultó más problemática que la que impulsaban las feministas de esa época y, de allí, la morigeración en su evaluación. ${ }^{20}$

En suma, las ideas y prácticas de las mujeres ácratas han sido conceptualizadas en relación con el feminismo a través de diversas variantes del mismo. Sin embargo aquellas, en sus intervenciones, se opusieron a una identidad feminista afirmando su identidad anarquista al considerar que la igualdad formaba parte del ideario. Esta situación genera cierto anacronismo desde los abordajes historiográficos que no se detienen en precisar a qué se refieren con feminismo y que obturan la mirada sobre la identidad política de aquellas mujeres. Laura Fernández Cordero señala que la visibilización de los emprendimientos femeninos genera "cierto efecto de esencialismo y excepcionalidad en los discursos de las mujeres libertarias" que obstaculiza situarlos como parte del movimiento

\footnotetext{
${ }^{16}$ Barrancos, op. cit., 276.

${ }^{17}$ Dora Barrancos, "Mujeres de "Nuestra Tribuna": el difícil oficio de la diferencia", Mora, no $2 /$ noviembre. 1996, 125-143,126.

${ }^{18}$ Offen, op.cit, 117.

${ }^{19}$ Offen, op.cit., 123.

${ }^{20}$ Maria Eugenia Bordagaray, "Apuntes sobre las relaciones entre anarquismo y feminismo en la argentina", Revista de estudios marítimos y sociales, $\mathrm{N}^{\circ}$ 4, 2011, 197-199.
} 
anarquista en su conjunto. ${ }^{21}$ Pero, también, su realización demuestra la necesidad de las militantes de enunciar su propia voz para denunciar que en la práctica aparecían las dificultades. Es decir, si bien el anarquismo $-\mathrm{y}$ así lo entendían varones y mujeres ácratas - conllevaba la idea emancipación femenina, las mujeres anarquistas pusieron de manifiesto que la diferencia sexual tensionaba la praxis libertaria.

\section{Las anarquistas y sus experiencias en la sociedad patriarcal: conciencia ante las injusticias, lucha por la trasformación social}

El termino feminismo, adquiere diversos significados dados por el referente, por "la realidad extralingüística designada" ${ }^{22}$ es decir, por el contexto sociocultural. En este sentido, nos resulta interesante en este trabajo retomar la definición que realiza Offen. Para la autora feminismo es un concepto "capaz de englobar una ideología y un movimiento de cambio sociopolítico fundado en el análisis crítico del privilegio del varón y de la subordinación de las mujer en cualquier sociedad dada". ${ }^{23}$ Adherimos a esta idea porque nos resulta más inclusiva y contemplativa de la diversidad de la experiencia empírica, a diferencia de otras apreciaciones más acotadas que sólo identifican al feminismo como el conjunto coherente de reivindicaciones de las mujeres organizadas. ${ }^{24}$

Retomaremos los criterios planteados por Offen para identificar ideas y prácticas feministas para analizar las intervenciones de las anarquistas en los diferentes períodos. La autora señala tres elementos a tener en cuenta,

1) que acepta la validez de las interpretaciones de las mujeres sobre sus propias experiencias y sus necesidades, y reconoce los valores que las mujeres defienden públicamente como propios (en contraposición al ideal estético de la feminidad inventado por los hombres) al enjuiciar su status en la sociedad con respecto a los hombres; 2) que se manifiesta consciente, molesta e incluso airada ante la injusticia (o la desigualdad) institucionalizada que los hombres como grupo ejercen sobre las mujeres como grupo en una sociedad determinada; y 3) que aboga por la eliminación de dicha injusticia y se opone al poder, a la fuerza o a la autoridad coercitiva que mantiene las prerrogativas del varón en esa cultura concreta, esforzándose por transformar las ideas dominantes y/o las instituciones y las prácticas sociales. Así pues, ser feminista significa necesariamente estar en conflicto con la cultura y la sociedad dominadas por el varón. ${ }^{25}$

\footnotetext{
${ }^{21}$ Laura Fernández Cordero, "Historiografía del anarquismo en la Argentina. Notas para debatir una nueva lectura", A Contracorriente, vol. 11, №3, pp. 41-67, 48.

${ }^{22}$ Pilar De Vega, 'Notas sobre la influencia de la situación sociocultural en el léxico: la palabra 'feminismo' (1940-1945)", Anuario de lingüística hispánica, vol. 6, 1990, pp. 115-134, 134.

${ }^{23}$ Offen op.cit., 130

${ }^{24}$ Ana De Miguel, "feminismos", Celia Amorós (coord.), 10 palabras clave sobre mujer, Navarra, EVD, 1995.

${ }^{25}$ Offen, op.cit., 131.
} 
Con estas premisas, a continuación, indagaremos de manera comparativa, los discursos femeninos en los periódicos La Voz...y Nuestra Tribuna y en la sección "La Página de la Mujer" del periódico Reconstruir para situar históricamente su agencia feminista. $^{26}$

\section{La Voz de la Mujer}

A fines del siglo XIX, la llegada masiva de inmigrantes - provenientes de Italia y España en su mayoría - reconfiguró las estructura social y económica, principalmente de las ciudades portuarias. La incorporación al mercado de trabajo no conllevó una mejora en las condiciones de vida de las/os trabajadoras/es. La explotación laboral, instaurada por los bajos salarios y las extensas jornadas en trabajos insalubres, afectó a los varones pero con más agudeza a las mujeres y las/os niñas/os que dada la imposición de roles sexualizados y jerarquizados del sistema patriarcal, fueron las/es explotadas/os dentro de la clase explotada. $^{27}$ Esta situación diferencial fue señalada por las redactoras de La Voz de la Mujer, pero su mirada se dirigió hacia la explotación laboral y simultáneamente, hacia la opresión de las mujeres por parte de los varones en los diversos espacios y roles sociales, en su relación con ellas como jefes, esposos, hermanos o padres. En sus propósitos reconocieron que en su experiencia como mujeres, no sólo como trabajadoras, su lugar había sido el "de ser el juguete, el objeto de los placeres de nuestros infames explotadores o de viles esposos". 28

La incursión en el espacio público a través de tomar la palabra para expresar su situación fue un arma novedosa para la época así como el lugar desde el que levantaron sus voz. En este sentido "una Stiratrice" -una lavandera-, denunciaba que en la sociedad en la que vivían, la mujer era la víctima de los caprichos, pasiones y tiranía del hombre y señalaba "nada más injusto es la desigualdad artificialmente establecida entre el hombre y la mujer". ${ }^{29}$ Así, ponía el acento en el carácter construido de la desigualdad y cuestionaba las ideas dominantes que sostenían el carácter natural e innato del dominio del varón. Mencionaba que su educación limitada, la vida doméstica al servicio del varón, su valor inferior en la escala social, todo ello, se concordaba para mantenerlas en un estado de dependencia económica y moral. ${ }^{30}$ La conciencia y molestia por la injusticia institucionalizada, retomando el segundo criterio de Offen, a las que se vieron sometidas

\footnotetext{
${ }^{26}$ Sobre la agencia feminista consultar Scott, op.cit.

${ }^{27}$ Graciela Queirolo, “mujeres que trabajan: una revisión historiográfica del trabajo femenino en la ciudad de buenos aires (1890-1940)", Nuevo Topo. Revista de historia y pensamiento crítico, n 3, septiembre-octubre, 2006, 29-48.

${ }^{28}$ La Voz de la Mujer. Periódico comunista -anárquico, n 1, 8 de enero, 1896. Cf. La Voz de la Mujer. Periódico comunista - anárquico, 2da. ed. Buenos Aires, Universidad Nacional de Quilmes, $2002,43$.

29 "Niente di piú ingiusto é la disuguaglianza stabilita artificiosamente tra l'uomo e la donna",Ibid. Cf. La Voz de la Mujer. Periódico comunista-anárquico, op. cit., 47.

${ }^{30}$ Estos cuestionamientos nos recuerdan a lo que más tarde las teóricas feministas denominarán sistema sexo/género .Nos referimos a las contribuciones de Simone de Beauvoir con su obra El segundo sexo editado por primera vez en 1949; Kate Millet con su libro Sexual Politics publicado en 1969 y Gayle Rubin con su ensayo El tráfico de mujeres. Notas sobre la "economía política” del sexo de 1975.
} 
sólo por el hecho de ser mujeres se repitió en todos los números, entre las firmas se destacaban, Pepita Guerra, Luisa Violeta, Rosario de Acuña, Carmen Lareva y María Muñoz.

Las mujeres de La Voz de la Mujer se manifestaron contra la desigualdad en relación con los varones, incluso, desafiaron a sus propios compañeros de ideas. La aparición del periódico suscitó conflictos- que se repitieron a lo largo del período como veremos después- que se hicieron públicos en los tres primeros números a través de las notas editoriales. Por un lado, se acusaba a las emprendedoras de sectorizar y dividir la lucha del anarquismo al situar la causa femenina independientemente de la cuestión social. Por otro lado, ellas inculpaban a sus compañeros anarquistas de que en la práctica en el hogar, en el sindicato y en el trabajo, sus actos no respondían a las ideas que propiciaban. Los consideraban falsos anarquistas y los interpelaban de manera directa, sin rodeos:

a pesar vuestro, ya lo veréis, haremos que "La Voz de la Mujer" se introduzca en vuestros hogares y que diga a vuestras compañeras que no sois tal leones, ni siquiera perros de presa (...) que hablan de libertad y sólo la quieren para sí, que hablan de anarquismo y ni siquiera saben... (...) vosotros los que habláis de libertad y en el hogar queréis ser zares. ${ }^{31}$

Los reclamos ante estas contradicciones entre el discurso y la práctica, llegaron a un momento culmine con la publicación de una denuncia contra el compañero Francisco Denambride, quien había disparado cinco veces contra su compañera Anita Lagouardette cuando decidió retirarse del domicilio que compartían "habiendo terminado su afinidad con él", decía la nota. Repudiando los disparos, de los cuales dos alcanzaron herir a la compañera, las redactoras dispararon sus plumas contra los que defendían al compañero, señalaban que "si hombres de esta especie pueden llamarse anarquistas y considerarse como tales ¿por qué no consideran también como tales a los burgueses y a los inconscientes que obran de idéntico modo?". Sintiéndose ellas defensoras del "Comunismo- Anárquico" y, por ende, "de la libertad de la mujer" su obligación era "estigmatizar el cobarde atentado del día 11 contra la libertad y la vida de una compañera" porque expresaban que éstas "no son cuestiones personales, sino causas que perjudican la idea". ${ }^{32}$

La interpelación a las compañeras "de trabajo e infortunios" que sufrían la doble esclavitud que ellas identificaban con "el capital y el hombre", no estaba dirigida simplemente a las/os militantes ácratas sino a todas las mujeres trabajadoras. ${ }^{33}$ En sus páginas solicitaban a los compañeros que circularan el periódico entre las compañeras en los talleres y fábricas, para acercarlas al comunismo-anárquico de corte individualista que

\footnotetext{
${ }^{31}$ La Voz de la Mujer. Periódico comunista -anárquico, n², 31 de enero, 1896. Cf. La Voz de la Mujer, op. cit., 58.

${ }^{32}$ La Voz de la Mujer.Periódico comunista-anárquico, n 5, 15 de mayo, 1896. Cf. La Voz de la Mujer, op. cit., 110.

${ }^{33}$ La Voz de la Mujer. Periódico comunista-anárquico, n ${ }^{\circ}$ 8, 14 de noviembre, 1896. Cf. La Voz de la Mujer, op. cit., 138.
} 
abrazaron como ideología y el que deseaban difundir a través del periódico. ${ }^{34}$ Para las mujeres de La Voz de la Mujer la emancipación femenina era uno de los ideales que defendía y constituía a la Anarquía y a través de ella se alcanzaría la igualdad entre el hombre y la mujer con lo cual se eliminaría la supremacía de los privilegios masculinos en la sociedad, podríamos decir entonces, que su postura responde al tercer criterio de la propuesta de Offen. $^{35}$

El periódico no ha tenido como destinatario de su mensaje a sujetos o corrientes feministas, en sus páginas el término feminismo no aparece y tampoco hay referencias a organizaciones feministas. Esto podría explicarse por la novedad del término, su uso, entendido como "sinónimo de emancipación de la mujer", se difundió en Francia a comienzos de la década del noventa del siglo XIX ${ }^{36}$ El único registro que encontramos de una interpelación a una organización de mujeres es a la Sociedad Alemana de Asistencia Deutscher Fraven Verein. La nota daba cuenta de la publicación del Boletín de la entidad el cual contenía un estudio sobre la prostitución - considerada una forma de esclavitud- en Buenos Aires y Montevideo. Las mujeres de La Voz de la Mujer, que se dirigían a sus congéneres llamándolas "queridas hermanas", elogiaron la iniciativa, pero realizaron algunas observaciones, dado que ellas, decían, las anarquistas "miramos más lejos, no nos concretamos a combatir a una sola clase de esclavitud; estamos contra todas". 37 Planteaban que la prostitución era producida por la miseria y encadenando causas y efectos, la causa de la miseria era la explotación y contra ella se debía combatir. Así, si bien podemos reconocer los criterios de Offen en las narrativas de estas mujeres, no podemos obviar que ellas comprendían que la Anarquía y su realización a través del comunismo-anárquico contenían entre sus principios la emancipación femenina y la igualdad entre varones y mujeres; por ello, no se identificaron como feministas, sino -señalaban en la primera editorial-como "comunistas anárquicas proclamando el derecho a la vida, o sea igualdad y libertad". ${ }^{38}$ Pero también denunciaron públicamente que como mujeres trabajadoras la explotación que sufrían era doble, reconociendo que aún entre sus propios compañeros, poner en práctica sus ideales en relación con las mujeres, resultaba problemático.

\footnotetext{
${ }^{34}$ Análisis sobre el discurso de estas mujeres y sus destinatarios en Nari y Feijoó, op. cit.; Bellucci, op. cit.; Francine Masiello (comp.), La mujer y el espacio público. el periodismo femenino en la argentina del siglo XIX, Buenos Aires, Feminaria editora, 1994; Eleonora Ardanaz, "Mujeres que levantan sus voces: aportes para el análisis de un discurso contrahegemónico", Actas del II Coloquio Nacional de investigadores en estudios del discurso, Universidad Nacional del Sur, 4al 6 de agosto, 2005; Laura Fernández Cordero, "Un ejercicio de lectura sobre el concierto de la prensa anarquista a partir de Mijaíl Bajtín (argentina, 18951925)", Adversus. revista de semiótica, 2013, pp. 68-91.

${ }^{35}$ La Voz de la Mujer. Periódico comunista -anárquico, n³, 20 de febrero, 1896. Cf. La Voz de la Mujer, op. cit., 71 .

${ }^{36}$ Offen, op.cit., 108.

${ }^{37}$ La Voz de la Mujer, Periódico comunista-anárquico, nº, 14 de noviembre, 1896. Cf. La Voz de la Mujer, op. cit ,132-133.

${ }^{38}$ La Voz de la Mujer, Periódico comunista-anárquico, ${ }^{\circ} 1,8$ de enero, 1896. Cf. . La Voz de la Mujer, op. cit, 43.
} 


\section{Nuestra Tribuna}

En el contexto de ebullición de la protesta social, enmarcada por los acontecimientos de la Semana Trágica en enero de 1919, cuando las huelgas obreras fueron reprendidas con masacres por parte de la policía y la Liga Patriótica y las huelgas de las/os trabajadoras/es rurales y urbanos de la Patagonia entre 1920 y 1922, aparece el segundo periódico anarquista escrito y dirigido por mujeres. En 1922 desde la ciudad de Necochea un grupo organizado por Juana Rouco Buela ${ }^{39}$ lanzó Nuestra Tribuna. Los dos epígrafes de la primera plana resumen el propósito y el posicionamiento que asumían al fundar un periódico, por un lado, demostrar que la inferioridad mental de la mujer era una mentira teológica. Por otro lado, enunciaban que "no hay emancipación de la mujer. La emancipación que nosotras mujeres libres, propiciamos, es social, netamente social". ${ }^{40}$ Así, se distinguían de los reclamos sufragistas y reformistas del feminismo de su época reafirmando su lugar de enunciación como mujeres anarquistas y al mismo tiempo, era una advertencia hacia los cuestionamientos que entre los compañeros pudieran surgir y que, después, igualmente se produjeron.

Del mismo modo que sus compañeras de La Voz de la Mujer a través de su experiencia como mujeres trabajadoras reconocían y denunciaban las desigualdades, pero haciendo hincapié en que los varones las mantenían en la ignorancia y esto era la causa de aquella desigualdad que impedía su educación racional y con ello su emancipación. ${ }^{41}$ Compartían con sus antecesoras la crítica a la vida familiar que sometía a las mujeres a la servidumbre, rechazaban el matrimonio y levantaban la bandera del amor libre, se diferenciaban de aquellas, -que se oponían al aborto y el control de la natalidad-, en la defensa a la maternidad consciente y voluntaria. Desde una perspectiva neomalthusiana, recomendaban a las mujeres que no tenían una educación y alimentación adecuada que se abstuvieran, decían, "de procrear, empleando para ello los medios de preservación científica que no menoscaban en modo alguno el acto fisiológico". 42 Además, en las páginas del periódico registraron su postura antimilitarista pero, a diferencia de otros tópicos, desde una perspectiva maternalista. ${ }^{43}$

Como señalamos en relación con las narrativas precedentes, las anarquistas de Nuestra Tribuna a partir de sus prácticas cotidianas en el ámbito familiar y laboral establecieron críticas al patriarcado, el cual definieron como un sistema instaurado para negarle los derechos a las mujeres, sometiéndola a una vida de humillación y sumisión,

\footnotetext{
39 Juana Rouco Buela, fue una militante ácrata que participó en la organización sindical de las trabajadoras a través de la Federación Obrera de la República Argentina (FORA) del quinto congreso, que proclamó defender los principios económicos y filosóficos del comunismo -anárquico. Consultar: Nadia Ledesma Prietto, y Gisela Manzoni, "Pluma, aguja y barricadas. Desafiando la hegemonía patriarcal", Adriana Valobra, (comp.), Mujeres en espacios bonaerenses, La Plata EDULP, 2009, 65-79.

${ }^{40}$ Nuestra Tribuna, $\mathrm{n}^{\mathrm{o}} 1,15$ de agosto de 1922, 1.

${ }^{41}$ Nuestra Tribuna, $\mathrm{n}^{\circ} 2,1^{\circ}$ de septiembre, 1922.

${ }^{42}$ Nuestra Tribuna, no 13,15 de abril, 1923.

43 Gisela Manzoni, "Antimilitarismo y antifascismo: particularidades de la intervención pública de las anarquistas argentinas", Cuadernos del Sur, N 41, 2012, 189-213.
} 
negándole un lugar en el espacio público. ${ }^{44}$ Sentenciaban que hasta el momento no se había demostrado científicamente por qué causas naturales o de otra clase la mujer era inferior al hombre, develando el carácter construido de la desigualdad.

Los conflictos con los compañeros sobrevinieron desde el comienzo y las redactoras arremetieron contra los que se opusieron a la salida del periódico poniendo el acento en las contradicciones que los atravesaban, ellas decían "hay muchos anarquistas y muy buenos compañeros, pero, que teóricamente aceptan la libertad de la mujer y que en la práctica obran de distinta manera en vez de educar a la compañera, no lo hacen...". 45

En el contexto en que se publicó Nuestra Tribuna, el movimiento anarquista era reprimido con firmeza. Las impulsoras del periódico sufrieron la persecución de las autoridades de Necochea y debieron trasladar la redacción del periódico en dos oportunidades. Además, el movimiento se encontraba dividido. Como señala Luciana Anapios algunos de los conflictos se vinculaban con: cuestiones personales; diferencias en los métodos y prácticas; el control de la imprenta y con las luchas que debía apoyar la Federación Obrera Regional Argentina (FORA). ${ }^{46}$ Nuestra Tribuna participó de estos conflictos adhiriendo al uso de la violencia y defendiendo el anti-centralismo, sus ideas se fundamentaban en una definición de la Anarquía amplia, sencilla y fácil de comprender, sostenían. ${ }^{47}$ Con su advenimiento se produciría la emancipación, así lo expresaba Juana Rouco Buela en su obra Mis Proclamas cuando convocaba a las mujeres a unirse al Ideal,

Y yo, hermanitas, os quisiera ver hurañas, rebeldes, anarquistas, cantoras de vuestras rabias, glosadoras de vuestro dolor, descriptoras de vuestros ensueños. Cantad vuestros rencores y vuestras rabias como tremendas proclamas de pelea (...) Pero no os deis por vencidas, hermanitas. Haced de vuestras lágrimas un buril, de vuestros clamores una piqueta, de vuestros sollozos una proclama y lanzaos en la lid de vuestras reivindicaciones emancipatorias. Poned vuestras protestas bajo las alas de la anarquía y marchad a conquistar la vida que os pertenece, que es vuestra, porque la habéis soñado bella, poética, amorosa. ${ }^{48}$

\footnotetext{
${ }^{44}$ Nuestra Tribuna, $\mathrm{n}^{\mathrm{o}} 3,15$ de septiembre, 1922.

${ }^{45}$ Nuestra Tribuna, $\mathrm{n}^{\mathrm{o}}$ 4, 15 de noviembre, 1922, 4.

46 Por un lado, estaba la corriente representada por la FORA y el periódico La Protesta, que se autolegitimaban como los representantes del movimiento anarquista centralizando bajo su órbita la organización de la prensa, las huelgas y los consejos; por otro lado, se ubicaban los gremios que no estaban bajo la FORA, grupos disidentes y el periódico La Antorcha, Pampa Libre e Ideas que defendían una postura anti-centralista y radicalizada en cuanto al uso de violencia. Consultar, Luciana Anapios, "El anarquismo argentino en los años veinte. tres momentos en el conflicto entre la protesta y la antorcha", Papeles de trabajo, año 2, no 3, junio, 2008; Juan Etchenique, Pampa libre. anarquistas en la pampa argentina, La Pampa, Universidad Nacional de Quilmes- Amerindia, 2000. Uno de los primeros análisis sobre la FORA fue realizado por Abad de Santillán en 1933, se puede consultar la reedición, Diego Abad de Santillán, La FORA. Ideología y trayectoria del movimiento obrero en la Argentina, Libros de Anarres, 2005.

${ }^{47}$ Nuestra Tribuna, $\mathrm{n}^{\circ} 1,15$ de agosto, 1922.

${ }^{48}$ Juana Rouco Buela, Mis proclamas, Santiago de Chile, editorial Lux. 1924, s/p.
} 
En Nuestra Tribuna destacaban que "la emancipación de la mujer no puede ser distinta a la del hombre". 49 Para ello, la mujer tenía que dejar de ser la esclava y sirvienta incondicional del hombre y no exclusivamente dedicarse al hogar, sino que, para modificar las ideas y prácticas imperantes como señala Offen en el tercer criterio, debía participar al igual que el varón en las luchas y en los sindicatos y tener acceso a la educación.

Las mujeres precisaron que su accionar respondía a su identificación como anarquistas, no se consideraban feministas y dejaron en claro que tampoco querían que las catalogaran así, de manera impetuosa interpelaban a quienes lo hacían: "nuestra hojita es un quincenario anarquista y como la anarquía no hace distingos de sexos, de ahí que hemos dicho todo (...) no se nos confunda con feministas (...) ya conocéis nuestros propósitos. Ellos son netamente sociales. No se apartan de los hombres que luchan por la emancipación humana. ¿Estamos?", 50

Cuando apareció el periódico, feminismo ya era una noción circulante pero tanto el término como lo que representaba, aún no estaba definido. Como señala Nari "si bien es cierto que en aquella época el término se empleaba, en líneas generales, para denunciar como injusta la situación social de las mujeres, la laxitud con la que se lo llegó a emplear posibilitó también su uso para defender y consolidar esa misma situación social". ${ }^{1}$ "Las redactoras de Nuestra Tribuna identificaron como feministas a las mujeres que así se autodenominaban, como por ejemplo, quienes habían organizado la Unión Feminista Nacional (conformada por el Consejo Nacional de Mujeres, el Centro Socialista Femenino y la Agrupación Socialista Femenina) que luchaban por el acceso a los derechos políticos, civiles y laborales de las mujeres a través de la interpelación al Estado. ${ }^{52}$ Para las anarquistas este camino era desacertado y en varios números atacaron ese proceder, distinguiéndose de la estrategia legalizante y de la búsqueda de participación política como vía para la emancipación de la mujer. Cuando apuntaron contra la Unión Feminista Nacional señalaban que "la emancipación -bajo el punto de vista humano- 'es social'. El feminismo está demás". Cuestionaban el posicionamiento de estas mujeres que, según las anarquistas expresaban "creen que por intermedio del sufragio feminista, delegando las mujeres sus intereses y derechos naturales a futuras diputadas y senadoras, pueden llegar gradualmente diplomáticamente y parlamentariamente a alcanzar su emancipación". ${ }^{3}$

La publicación en Nuestra Tribuna de un análisis del movimiento feminista en Estados Unidos y Francia realizado por Federica Montseny, destacada militante española, nos permite presentar algunas inflexiones discursivas, al menos, en cuanto a las consideraciones sobre el feminismo. La joven sostenía que el movimiento había fracasado en aquellos países pues no había conseguido avances respecto a los derechos políticos. Indicaba que esta era una cuestión que le desinteresaba como anarquista, pero como mujer

\footnotetext{
${ }^{49}$ Nuestra Tribuna, $\mathrm{n}^{\circ}$ 9, 15 de enero, 1923, 1.

${ }^{50}$ Nuestra Tribuna, $\mathrm{n}^{\circ} 1,15$ de agosto, 1922, 1 .

51 Marcela Nari. "Feminismo y diferencia sexual. Análisis de la "encuesta feminista argentina" de 1919", Boletín del Instituto de Historia Argentina y Americana "Dr. Emilio Ravignani", 3era. serie, n” 12, II semestre, 1995, 61-86, 79. Disponible en http://ravignanidigital.com.ar/_bol_ravig/n12/n12a03.pdf.

${ }^{52}$ Una interesante reflexión sobre esta cuestión en Adriana Valobra,"El Estado y las mujeres, concepciones en clave feminista", Estudios sociales del Estado, $\mathrm{N}^{\circ} 1,2015,32-57$

${ }^{53}$ Nuestra Tribuna, $\mathrm{n}^{\circ} 2,1^{\circ}$ de septiembre, 1922.
} 
y por lo que significaba, no por el hecho en sí mismo, le generaba interés. Para ella aquella situación era el reflejo de la posición subordinada de la mujer en la sociedad. Subordinación que era reproducida por algunos compañeros de ideas, que, según Montseny, exigían su absoluta emancipación y en el fondo pensaban que no se podía vivir con una mujer emancipada. Todo esto, decía, era la muestra de la pervivencia del principio de propiedad y de autoridad y del dominio del más fuerte. ${ }^{54}$

Nuestra Tribuna culminó en 1925, años después Juana reflexionaba sobre esta experiencia como un sueño hecho realidad que tuvo como fin "demostrar con hechos que la capacidad de la mujer es exactamente igual que la del hombre, y solo le falta ejercicio y estímulo, ya que siempre se la ha ido colocando en un plano inferior de condiciones...".55 En sus páginas, las mujeres revelaron esta situación y además señalaron que la educación (no oficial), el conocimiento de las ideas libertarias y la participación en la luchas eran las herramientas para poder superarla. Es decir, la responsabilidad de revertir la desigualdad recaía en última instancia en las propias mujeres y en los compañeros de éstas. Las redactoras se identificaron como anarquistas y al igual que en el caso de La Voz..., subrayaron que existía una diferencia de género en la aplicación de los principios de igualdad y libertad que conllevaba su posicionamiento ideológico. Se enfrentaron al feminismo sufragista pues lo consideraban una corriente reformista que se preocupaba por la participación de las mujeres en la política partidaria y que demandaba al Estado este derecho. Estas reivindicaciones les eran ajenas, aunque también les preocupaban, como señaló Montseny porque los retrocesos y los avances en materia de derechos conmovían a las mujeres como grupo, cualquiera sea su perspectiva política.

\section{La Página de la Mujer}

Los estudios sobre el movimiento ácrata, en su mayoría, rotulan a los contextos represivos como marco para la oclusión del movimiento. ${ }^{56}$ Este límite temporal, definido entre el Centenario de la Revolución de Mayo y el golpe de Estado de 1930, es señalado como una de las características principales del sentido común historiográfico sobre el anarquismo argentino. $^{57}$ Durante la década de 1930, hasta el momento, no se han encontrado publicaciones específicamente femeninas, pero sí encontramos notas escritas por mujeres en la revista anarquista Nervio (1931-1936). ${ }^{58}$ Por ejemplo, las pedagogas anarquistas María Lacerda de Moura desde Brasil y Haydee Maciel desde la ciudad de Rosario, provincia de Santa Fe intervinieron reiteradamente tratando temas como el malthusianismo,

\footnotetext{
${ }^{54}$ Federica Montseny, “Comentarios”, Nuestra Tribuna, año 2, n 13, 15 de febrero, 1923, 3.

55 Juana Rouco Buela, Historia de un ideal vivido por una mujer, Buenos Aires, s/e, 1964.83.

${ }^{56}$ Barrancos, Anarquismo, educación..., op. cit; Juan Suriano, Anarquistas, cultura y política libertaria en Buenos Aires, 1890-1910, Buenos Aires, Manantial, 2001.

${ }^{57}$ Agustín Nieto, "Notas críticas sobre el sentido común historiográfico", A contracorriente, vol. 7, n.3, spring, 2010, 219-248.

${ }^{58}$ Se publicaron 48 números entre mayo de 1931 hasta noviembre de 1936.
} 
el lugar de la mujer en la sociedad, la Escuela Nueva, entre otros. ${ }^{59}$ Asimismo, durante este período las mujeres asumieron un papel destacado en la lucha antifascista. Dentro del anarquismo local, algunas de sus militantes participaron en el frente durante la Guerra Civil Española, tal el caso de la abogada Anita Piacenza (Nita Nahuel) o formaron parte de colectivos como la Agrupación Femenina Antiguerrera (AFA) y los comités de Solidaridad Internacional Antifascista (SIA). ${ }^{60}$

Días después del inicio del mandato presidencial de Juan Domingo Perón, en la primera quincena de junio de 1946, se editó el primer ejemplar del periódico Reconstruir que contenía 'La Página de la Mujer', una columna escrita por mujeres donde aparecen como asiduas colaboradoras Herminia Brumana, Ana Piacenza, Emilia Goyena e Iris Pavón. ${ }^{61}$ En contraste con los periódicos que abordamos anteriormente, éste buscaba difusión entre un público amplio, no sólo entre quienes tenían afinidades ácratas y tampoco circunscribió su mensaje a los sectores trabajadores.

Reconstruir fue el órgano de difusión de las actividades de la agrupación Unión Socialista Libertaria que se conformó en Rosario ese mismo año. Entre sus contenidos se destacaban la situación de la juventud universitaria, los sindicatos y las luchas del sector trabajador y profesional; abordó el escenario internacional y el nacional con una fuerte crítica al peronismo y todas sus políticas, las cuales identificaban como la avanzada del fascismo europeo en el ámbito local.

En los primeros números Herminia Brumana figuraba como editora de la columna y parece haber sido quien escribía las notas no firmadas. A partir de los últimos números de 1947, la página dedicada a las mujeres aparecerá de manera intermitente y se irá convirtiendo en escasos recuadros sobre temas relacionados con la actualidad política. Si consideramos el período 1946-1952, la última referencia a las mujeres aparece en el número inmediatamente posterior a las elecciones presidenciales del año 1951 cuando triunfa nuevamente el peronismo. En general, realizaron observaciones críticas de las políticas del gobierno peronista que afectaban a las mujeres, en menor medida, se publicaron artículos sobre situaciones que podrían experimentar algunas de las autoras. En este sentido, en el primer número la página desplegó un dilema propio de madres de clase media-alta: el cuidado de las/os niñas/os cuando tenían que salir a cenar o al teatro. La solución que Brumana recomendaba, que ya había sido implementada en Estados Unidos, era el servicio de niñeras. ${ }^{62}$ Aquí podemos evidenciar ciertas discontinuidades en las prácticas discursivas de las mujeres anarquistas que desarrollamos en los apartados

\footnotetext{
${ }^{59}$ Un breve recorrido por la obra de Maria Lacerda de Moura en Adalaide Gonçalves; Allyson Brunoy Camila Queiroz, "A anarquista María Lacerda de Moura: emancipação e palavra empenhada”, María Lacerda de Moura, Renovação, 1919, Brasil, Edições UFC, 2015.

${ }^{60}$ Consultar, María Eugenia Bordagaray, "Luchas antifascistas y trayectorias generizadas en el movimiento libertario argentino (1936-1955)", Cuadernos de H Ideas, Vol. 7, № 7, 2013.

${ }^{61}$ Se editaron 90 números hasta junio de 1959 cuando cambia de formato y se publica como revista hasta marzo de 1976. Entre 1952 y 1955 el periódico fue clausurado y no pudo publicarse. Para contrarrestar esta ausencia los redactores crean la editorial Radar y difunden clásicos de la literatura anarquista y de militantes ácratas locales en formato de libros durante esos años.

${ }^{62}$ Herminia Brumana, "Problemas resueltos", Reconstruir, no 1, 1era. quincena de junio, 1946, 14.
} 
precedentes. Las mismas podrían vincularse con el distinto origen social de las autoras como de las destinatarias de los enunciados plasmados en el periódico Reconstruir.

Las intervenciones, principalmente, respondían a un maternalismo político, ${ }^{63}$ es decir, un posicionamiento que destacaba la función social de la maternidad para demandar derechos e intervenir en el espacio público. Sobre esta cuestión podemos trazar una línea de continuidad con las redactoras de Nuestra Tribuna; igualmente, esto puede señalarse en relación con la importancia que le otorgaron a la educación como medio para la emancipación. Emilia Goyena, de quien sólo sabemos que fue exiliada en la Argentina después de la Guerra Civil española, utilizaba una interrogación para el título de sus notas, “¿mujer que piensas?”, en ellas criticaba las acciones de la iglesia que mantenía a la mujer en la ignorancia y el sometimiento. Para la autora, la clave de superación de la mujer estaría en la educación moral para que, sobre todo a través de su rol de madres, pudieran gestar hogares "revolucionarios" y hombres nuevos. La mujer formaría parte de la nueva sociedad asumiendo el papel de educadora de sus hijos, de su rol revolucionario como madre iluminada e iluminadora. El discurso maternalista de las anarquistas que escribían en 'La Página de la Mujer', puede encontrar su explicación en el contexto político de actuación. Efectivamente, en pos de captar un público que se había subyugado con algunas intervenciones más convencionales -aunque no todas- por parte de Eva Perón, tuvieron que encontrar nuevos tonos a sus postulaciones.

Retomando las críticas de algunos varones que creían que la cabeza de la mujer sólo servía para llevar sombreros, Goyena instaba a las mujeres a pensar, "si piensas, mujer, demostraremos que con sombrero o sin él, tu cerebro funciona unido al sentimiento y que la Humanidad puede esperar mucho bueno de ti. Tal vez, todo lo bueno que los hombres nos han sabido dar". ${ }^{64}$ Entre este posicionamiento discursivo y el de las mujeres de La Voz de la Mujer y de Nuestra Tribuna, aunque marcamos algunas permanencias, cuando consideramos la radicalidad en la enunciación y el contenido, las diferencias afloran. Anarquismo y feminismo ya no representaban lo mismo que décadas atrás porque las condiciones económicas, políticas, sociales y de género se habían modificado y esto se manifiesta en análisis de la columna femenina.

La mayoría de las mujeres que participaron en la página pertenecían a la Unión de Mujeres Socialistas Libertarias. Creada en 1946, en su declaración de principios podemos entrever la mirada que tenían sobre el lugar de las mujeres en relación con los varones. Se proponían luchar por la "igualdad de todos los derechos para hombres y mujeres (...) protección a la maternidad. Maternidad consciente. Protección a las mujeres que trabajan”, entre otras cuestiones. Ellas reconocían que los valores que las identificaban, el socialismo y la libertad, se hallaban más difíciles de alcanzar para las mujeres que para los varones "...por lo tanto, más dignos de luchar por conquistarlos" sentenciaban. ${ }^{65}$ Esta cuestión,

\footnotetext{
${ }^{63}$ Marcela Nari, Políticas de maternidad y maternalismo político. Buenos Aires, 1890-1940, Buenos Aires, Biblos, 2004.

${ }^{64}$ Emilia Goyena, “Mujer ¿qué piensas?”, Reconstruir, № 5, 2da. quincena de agosto, 1946, 9.

${ }^{65}$ Unión de Mujeres Socialistas Libertarias "Declaración de principios", Reconstruir, No 1, 1era. quincena junio, 1946, 13-14, 14.
} 
suponemos, es la que promovió la necesidad de formar una agrupación exclusiva de mujeres, dado que se crea casi al mismo tiempo que la Unión Socialista Libertaria.

El debate por los derechos políticos femeninos provocó que las mujeres tomaran posición sobre este tema y aquí encontramos algunos giros en las conceptualizaciones respecto a las intervenciones de las anarquistas de fines del siglo XIX y el primer cuarto de siglo XX. Como mencionamos, las inflexiones discursivas cobran sentido si tenemos en cuenta la trama contextual en la que se producen. Piacenza fue la encargada de interpelar las mujeres a través del título "amiga, ¿quiere usted votar?”. Apuntaba en primer lugar que era necesario capacitarse y liberarse de la tutela e influencia masculina para poder ejercer esos derechos considerados por la autora como secundarios. Luego, realizó una distinción entre sufragismo y feminismo. Este era entendido como, "un amplio movimiento de opinión que abarca no solamente a mujeres sino también a hombres y cuyo fin es la emancipación total de la mujer. No comprende solamente los derechos políticos, sino y principalmente a los civiles, económicos, sociales y sexuales". Sufragismo, señalaba "significa el ejercicio de la función electoral, la práctica del voto". "66 Como señala Bordagaray, "en función de dar una respuesta al sufragismo que propiciaba el gobierno" las anarquistas tuvieron que realizar esta distinción. ${ }^{67}$ El agenciamiento político sobre las mujeres de Eva Duarte y Juan Perón, impulsó a las mujeres ácratas a definir su posición en relación con este nuevo sujeto político. En este sentido, en nombre de las/os socialistas libertarias/os Piacenza señaló que ellas/os creían en el feminismo y no en el sufragismo.

Casi veinticinco años después del enfrentamiento con el feminismo sufragista en las páginas de Nuestra Tribuna, las mujeres de la última actuación exclusivamente femenina en la prensa anarquista adhirieron al feminismo para posicionarse contra el peronismo.

Las diferencias, además, se vinculan con los cambios producidos en el anarquismo. La ampliación de la base social del movimiento libertario local para compensar la pérdida de fuerza como agencia de la clase trabajadora, produjo una reactivación de su dimensión cultural e ideológica y su incidencia en nuevos ámbitos. Las/os militantes ácratas, apoyándose en sectores de la clase media profesional, de la que muchos formaban parte, volcaron sus esfuerzos en los circuitos, relaciones y proyectos culturales, como estrategia para conjurar la contracción de su presencia en el movimiento obrero. Es decir, podemos inscribir las variaciones en el disímil escenario político y social en el que se desenvolvió el movimiento anarquista y sus sostenedoras/es luego de 1930 cuando además de la represión y persecución, otras variables pesaban, como la competencia con el comunismo por el agenciamiento del sector trabajador y la creciente intervención del Estado en todas las dimensiones de la vida social.

En relación con los reclamos sobre la situación de las mujeres en la sociedad respecto a los varones, - retomando los criterios de Offen- estos fueron medrosos en comparación con las anteriores publicaciones. Se observa en el análisis el reconocimiento de la desigualdad, pero no se ahondó en esta cuestión, sólo podríamos señalar a la educación y la apuesta por el socialismo libertario como herramientas para superarla. En

\footnotetext{
${ }^{66}$ Anita Piacenza, “Amiga ¿quiere usted votar?”, Reconstruir, año 1, nº 2, 2da. quincena junio, $1946,11$.

67 María Eugenia Bordagaray, Controversias libertarias: la interpelación anarquista en tiempos del peronismo. Tesis de posgrado, La Plata, UNLP, 2014, 129.
} 
este sentido, también podemos señalar que a diferencia de las mujeres que escribían en $L a$ Voz de la Mujer y Nuestra Tribuna, quienes para interpelar a sus congéneres se posicionaban en un lugar inclusivo de enunciación a partir del uso de pronombres como 'Nosotras' y términos como 'Hermanas', 'Compañeras'. En 'La Página de la Mujer', no se observa ese reconocimiento de igualdad y la comunión de experiencias, sino que la interpelación a las mujeres se producía, en mayor medida, en tanto su rol de madres. Piacenza, únicamente, llamó a las destinatarias de su intervención 'Amiga'. En conjunto, las modalidades de enunciación de estas últimas acometedoras, conllevaban un componente prescriptivo, siguiendo a Eliseo Verón, que pretendía iluminar a las mujeres, sacarlas de la ignorancia que no les permitía cuestionar las acciones del gobierno y la iglesia en particular. $^{68}$

\section{A modo de cierre}

A partir de lo analizado en las tres producciones, desde una mirada panorámica, podemos decir que en algunas con más contundencia y en otras con menos, logramos distinguir los criterios planteados por Offen para identificar una idea o sujeto feminista. Ahora bien, si a partir de esta propuesta afirmáramos que las mujeres ácratas eran feministas nos resulta incómodo si conjuntamente no damos cuenta, por un lado, del posicionamiento que las propias mujeres expresaron sobre sus prácticas y por otro lado, de las interpretaciones que manifestaron sobre el feminismo de su tiempo. Asimismo, teniendo en cuenta la interseccionalidad con la cuestión de clase y la ideología, las generalizaciones son aún más difíciles de hacer y la homogeneidad sobre la identificación de las mujeres se diluye. La cuestión de género está afectada por estas diferencias y es necesario señalarlas sin enfatizar alguna sobre otra, sino de manera unificada, siendo cada una parte de cualquier posible definición de las intervenciones de las mujeres anarquistas y por ende de ellas mismas. ${ }^{69}$ Las inflexiones discursivas a lo largo del período estudiado nos demuestran que, siguiendo a Donna Haraway, el conocimiento es situado, no sólo al hacer explícito nuestro posicionamiento, sino también el de nuestros sujetos de estudio. ${ }^{70}$ En este caso, reflexionamos sobre los usos del feminismo para identificar el posicionamiento de las ácratas a través del estudio situado de las propias manifestaciones de las mujeres.

Pensar sobre los vínculos entre anarquismo(s) y feminismo(s) nos permite abrir, desde nuestro presente, una serie de interrogantes, entre ellos; ¿Si las mujeres anarquistas son consideradas como la vanguardia del feminismo por qué no se plantea esto para el/los anarquismo(s) en general?; ¿Los anarquismos son consustancialmente feministas?; ¿Se pueden pensar espacios políticos de izquierda que incluyan el/los feminismo(s) en sus plataformas sin la necesidad de organizar espacios feministas anexos?; ¿La

\footnotetext{
${ }^{68}$ Eliseo Verón, "La palabra adversativa" de Eliseo Verón, AA.VV, El discurso político. Buenos Aires, Hachette, 1987, 11-26.

${ }^{69}$ Sobre interseccionalidad consultar. Karina Bidaseca, “"'Los peregrinajes de los feminismos de color en elpensamiento de María Lugones”, Estudos Feministas, 22, (3): 320, setembro-dezembro, 2014, 953-964.

${ }^{70}$ Donna Haraway, Ciencia, cyborgs y mujeres. La reinvención de la naturaleza, Madrid, ediciones Cátedra, 1995.
} 
interseccionalidad puede ser una herramienta para conformar espacios políticos que incluyan todas las diferencias en sus demandas?. Este trabajo, no pretendió agotar estos cuestionamientos, sino que intentó ser una excusa para reflexionar nuestras propias intervenciones a través del examen del posicionamiento de las ácratas y así contribuir a la discusión de estos temas, todavía tan presentes.

\section{Bibliografía}

\section{-Fuentes}

Brumana, Herminia, "Problemas resueltos", Reconstruir, n 1, 1era. quincena de junio, 1946, 14. Goyena, Emilia, "Mujer ¿qué piensas?”, Reconstruir, no 5, 2da. quincena de agosto, 1946, 9.

La Voz de la Mujer. Periódico comunista -anárquico (1896-1897), 2da ed. Buenos Aires, Universidad Nacional de Quilmes. 2002.

María Lacerda de Moura, Renovação, 1919, Brasil, Edições UFC, 2015.

Nuestra Tribuna, hojita del sentir anárquico femenino (1922-1925), Bahía Blanca, Universidad Nacional del Sur, 2005.

Piacenza, Anita, “Amiga ¿quiere usted votar?”, Reconstruir, año 1, n 2, 2da. quincena junio, 1946, 11.

Rouco Buela, Juana, Historia de un ideal vivido por una mujer, Buenos Aires, s/e, 1964

Rouco Buela, Juana, Mis proclamas, Santiago de Chile, editorial Lux. 1924. Disponible en http://ideasfem.wordpress.com/textos/e/e09/.

Unión de Mujeres Socialistas Libertarias, "Declaración de principios", Reconstruir, no 1, 1era. quincena junio, 1946, 13-14.

\section{-bibliografía general}

Abad de Santillán, Diego. La FORA. Ideología y trayectoria del movimiento obrero en la argentina. Buenos Aires: Libros de Anarres, 2005.

Anapios, Luciana, "el anarquismo argentino en los años veinte. tres momentos en el conflicto entre la protesta y la antorcha", Papeles de trabajo, año 2, $\mathrm{n}^{\mathrm{o}} 3$, junio, 2008. Disponible en http://www.idaes.edu.ar/papelesdetrabajo/paginas/documentos/03_1_art\%c3\%adculo_luciana_anap ios.pdf.

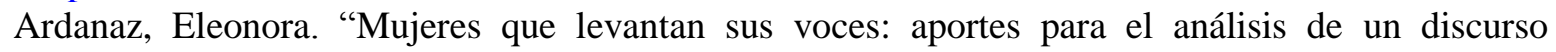
contrahegemónico", Actas del II Coloquio Nacional de investigadores en estudios del discurso, Universidad Nacional del Sur, 4 al 6 de agosto, 2005. Disponible en

http://www.fl.unc.edu.ar/aledar/hosted/3ercoloquio/213.pdf.

Barrancos, Dora, "Mujeres de "Nuestra Tribuna": el difícil oficio de la diferencia", Mora, $\mathrm{n}^{\circ}$ 2/noviembre, 1996, 125-143.

Barrancos, Dora, Anarquismo, educación y costumbres en la argentina de principios de siglo, Buenos Aires, Contrapunto, 1990.

Bellucci, Mabel, “Anarquismo y feminismo", El libertario, año 21, n 67, 2006.

Bellucci, Mabel, "De la pluma a la imprenta", Fletcher, Lea. (comp.), Mujer y cultura en la argentina del siglo XIX, Buenos Aires, Feminaria editora, 1994, 252-262.

Bordagaray, Maria Eugenia. 2011. "Apuntes sobre las relaciones entre anarquismo y feminismo en la argentina". Revista de estudios marítimos y sociales, $\mathrm{n}^{\circ} 4$. 
Bordagaray, María Eugenia, "Luchas antifascistas y trayectorias generizadas en el movimiento libertario argentino (1936-1955)", Cuadernos de H Ideas, Vol. 7, $\mathrm{N}^{\mathrm{o}}$ 7, 2013. http://perio.unlp.edu.ar/ojs/index.php/cps/article/view/2064/1810.

De Miguel, Ana, "feminismos", Amorós, Celia (coord.), 10 palabras clave sobre mujer, Navarra, EVD, 1995.

De Vega, Pilar, "Notas sobre la influencia de la situación sociocultural en el léxico: la palabra 'feminismo' (1940-1945)”, Anuario de lingüística hispánica, vol. 6, 115-134, 1990.

Eliseo Verón, "La palabra adversativa" de Eliseo Verón, AA.VV, El discurso político. Buenos Aires, Hachette, 1987, 11-26..

Etchenique, Juan, Pampa libre. Anarquistas en la pampa argentina, La Pampa, Universidad Nacional de Quilmes- Amerindia, 2000.

Fernández Cordero, Laura, "Izquierdas y feminismos, hitos contemporáneos", Nueva Sociedad, 261, Enero - Febrero, 2016, 116-127. Disponible en http://nuso.org/media/articles/downloads/7.TC_Fernandez_261.pdf.

Fernández Cordero, Laura "Historiografía del anarquismo en la Argentina. Notas para debatir una nueva lectura", A Contracorriente, vol. 11, N 3, 2014, 41-67. Disponible en http://acontracorriente.chass.ncsu.edu/index.php/acontracorriente/article/view/830.

Fernández Cordero, Laura, "Un ejercicio de lectura sobre el concierto de la prensa anarquista a partir de Mijaíl Bajtín (argentina, 1895-1925)”, Adversus. Revista de semiótica, Buenos Aires, 2013, 68-91.

Gonçalves, Adalaide; Bruno, Allyson y Queiroz, Camila, “A anarquista María Lacerda de Moura: emancipação e palavra empenhada", María Lacerda de Moura, Renovação, 1919, Brasil, Edições UFC, 2015.

Guzzo, Cristina, Las anarquistas rioplatenses (1890-1990), EEUU, Orbis Press, 2003.

Haraway, Donna, Ciencia, cyborgs y mujeres. La reinvención de la naturaleza, Madrid, ediciones Cátedra, 1995.

Karen Offen, "Definir el feminismo: un análisis histórico comparativo", Historia Social, $\mathrm{N}^{\circ}$ 9, invierno, 1991, 103-135.

Ledesma Prietto, Nadia y Manzoni, Gisela, "Pluma, aguja y barricadas. Desafiando la hegemonía patriarcal", Adriana Valobra, (comp.), Mujeres en espacios bonaerenses, La Plata EDULP, 2009, 65-79.

Manzoni, Gisela, "Antimilitarismo y antifascismo: particularidades de la intervención pública de las anarquistas argentinas", Cuadernos del Sur, N 41, 2012, 189-213.

María Eugenia Bordagaray, Controversias libertarias: la interpelación anarquista en tiempos del peronismo. Tesis de posgrado, La Plata, UNLP, 2014.

Masiello, Francine (comp.), La mujer y el espacio público. El periodismo femenino en la argentina del siglo XIX, Buenos Aires, Feminaria editora, 1994.

Molineaux, Maxine, "Ni dios, ni patrón, ni marido. Feminismo anarquista en la argentina del siglo XIX", La voz de la mujer. Periódico comunista -anárquico, 2da. ed. Buenos Aires, Universidad Nacional de Quilmes, 2002, 11-40.

Nari, Marcela y Feijoó, María del Carmen, "Imaginando al lector/ la lectora de la voz de la mujer", Fletcher, Lea (comp.), Mujer y cultura en la argentina del siglo XIX, Buenos Aires; Feminaria editora, 1994, pp.276-284.

Nari, Marcela, "El feminismo frente a la cuestión de la mujer en las primeras décadas del siglo XX", Suriano, Juan (comp.), La cuestión social en argentina, 1870-1943, Buenos Aires, La colmena, 2004. 
Nari, Marcela, "Feminismo y diferencia sexual. Análisis de la "encuesta feminista argentina" de 1919”, Boletín del Instituto de Historia Argentina y Americana "Dr. Emilio Ravignani", 3era. serie, $\mathrm{n}^{\circ}$ 12, II semestre, 1995, 61-86. Disponible en http://ravignanidigital.com.ar/_bol_ravig/n12/n12a03.pdf.

Nari, Marcela, Políticas de maternidad y maternalismo político. Buenos Aires, 1890-1940, Buenos Aires, Biblos, 2004.

Nieto, Agustín, "Notas críticas sobre el sentido común historiográfico", A Contracorriente, vol. 7 , $\mathrm{n}^{\circ} .3$, spring, 2010, 219-248.

Palomera Valenzuela, Adriana, "La mujer anarquista: Discursos en torno a la construcción de sujeto femenino revolucionario en los albores de la "idea"', Izquierdas, $\mathrm{N}^{\circ} 24$, Julio, 2015. Disponible en: https://dx.doi.org/10.4067/S0718-50492015000300008

Queirolo, Graciela, "Mujeres que trabajan: una revisión historiográfica del trabajo femenino en la ciudad de Buenos Aires (1890-1940)", Nuevo Topo. Revista de historia y pensamiento crítico, $\mathrm{n}^{\circ} 3$, septiembre-octubre. 2006, 29-48.

Scott, Joan, Las mujeres y los derechos del hombre. Feminismo y sufragio en Francia, 1789-1944, Buenos Aires, Siglo XXI, 2012.

Suriano, Juan, Anarquistas, cultura y política libertaria en buenos aires 1890-1910, Buenos Aires, Manantial, 2001.

Valobra, Adriana, "El Estado y las mujeres, concepciones en clave feminista", Estudios sociales del Estado, Nㅜ1, 2015, 32-57.

Verón, Eliseo, "La palabra adversativa" de Eliseo Verón, AA.VV, El discurso político. Buenos Aires, Hachette, 1987, 11-26.

Vicente, Laura, "El feminismo anarquista desde sus orígenes internacionalistas a Mujeres Libres", Viento Sur, $\mathrm{N}^{\circ} 136$, octubre, 2014, 90-98. Disponible en,

https://vientosur.info/IMG/pdf/VS136_L_Vicente_El_feminismo_anarquista_desde_sus_origenes_i nternacionalistas a Mujeres Libres.pdf. 